\title{
261. TIPIFICACIÓN DEL NOMBRE LINNEANO YUCCA GLORIOSA (AGAVACEAE)
}

\author{
P. Pablo FERRER-GALLEGO ${ }^{1,2}$, Daniel GUILLOT ${ }^{3} \&$ Emilio LAGUNA $^{1}$
}

Recibido el 15 de junio de 2015, aceptado para su publicación el 20 de junio de 2015

Typification of the Linnaean name Yucca gloriosa (Agavaceae)

Palabras clave. Agavaceae, Linneo, lectotipo, nomenclatura, Yucca gloriosa.

Keywords. Agavaceae, Linnaeus, lectotype, nomenclature, Yucca gloriosa.

Dentro del género Yucca L. (Agavaceae), Yucca gloriosa L. es originaria del sureste de los Estados Unidos, pero ha sido ampliamente cultivada como ornamental, lo que ha provocado que llegue a asilvestrarse en muchos territorios. Se diferencia de Y. aloifolia L. por su tallo corto o nulo, hojas lisas en el margen, flores con pedúnculo de 1-2 cm, inflorescencias laxas y con ramas más o menos erectas, mientras que Y. aloifolia presenta un tallo robusto y ramoso, hojas denticuladas, flores con pedúnculo de 2-3 cm, inflorescencias más o menos densas y ramas algo colgantes (Höchstatter, 2002).

Habita en dunas o en playas a lo largo de la costa, de Louisiana a Florida, y al norte hasta Carolina del Sur, siendo también cultivada al igual que en estas zonas citadas a lo largo de la costa del Golfo de México, en los desiertos de Arizona, asilvestrándose en California, y siendo común en el Mediterráneo y en las zonas templadas de todo el mundo (Irish \& Irish, 2000). Esta especie presenta gran variabilidad en cuanto a sus hojas, distinguiéndose numerosas variedades, formas cultivadas e híbridos (Houtte, 1880; Trelease, 1902; Molon, 1914; Sprenger in Schwerin, 1920). Höchstatter (2002) indica que actualmente en las colecciones europeas existen muchas formas híbridas producidas en los siglos XVIII y XIX. Según este autor, las numerosas formas encontradas en el Mediterráneo son probablemente híbridos producidos en el siglo XIX por el botánico y floricultor alemán Carl Ludwig Sprenger (1846-1917), y añade que deben existir asimismo híbridos de $Y$. gloriosa y $Y$. aloifolia.

Desde el punto de vista nomenclatural, para el nombre Yucca gloriosa no ha sido designado su correspondiente tipo. En el presente trabajo se aborda la lectotipificación de este nombre a partir del estudio del material citado en el protólogo y los pliegos de herbario que contienen material original de Linneo.

\section{Tipificación}

Linneo (1753: 319) toma la nomina legitima specifica "Yucca foliis integerrimis" directamente de su obra Viridarium Cliffortianum (Linneo, 1737: 29), nombre que no está acompañado de ninguna ilustración, al tiempo que cita en el protólogo hasta cuatro sinónimos: 1) "Yucca foliis margine integerrimis" obtenido de dos de sus obras anteriores: Hortus Cliffortianus (Linneo, 1738: 130) y Hortus Upsaliensis (Linneo, 1748: 88 ), de las que también obtiene la indicación locotípica que aparece en el protólogo; 2) "Yucca foliis aloës" de Bauhin (1623: 91); 3) "Yucca indica, foliis aloës" de Barrelier (1714: 70), y 4) “Cordyline foliis pungentibus integerrimis" de Royen (1740: 22). Pero de todos los sinónimos incluidos directamente en 


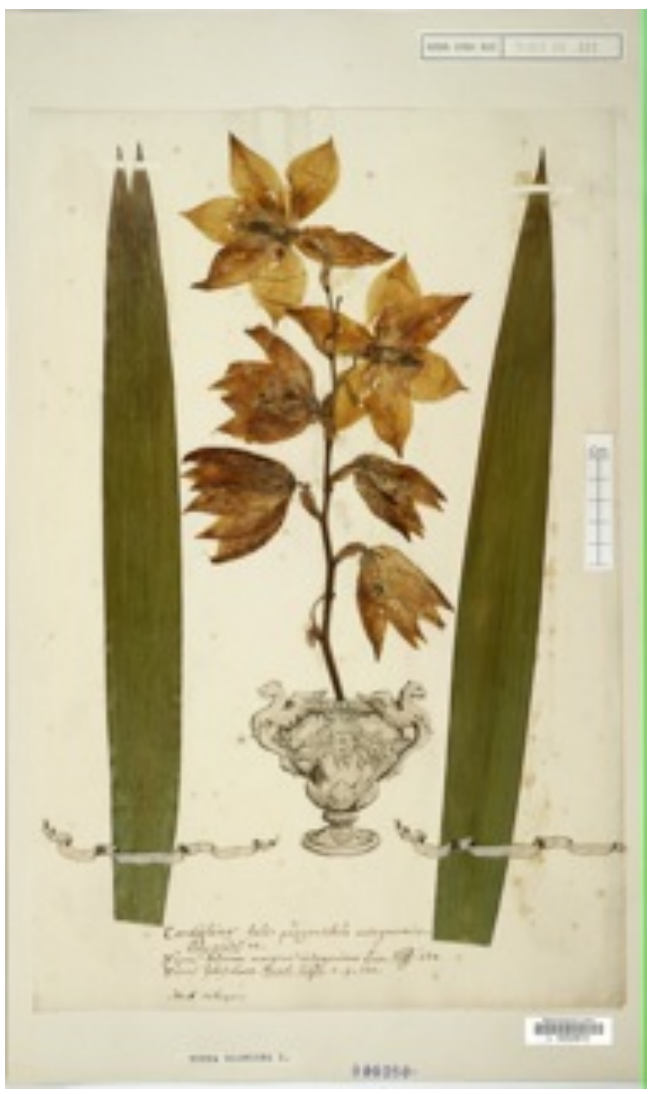

Figura 1. Lectotipo de Yucca gloriosa L., Herb. Adriaan van Royen [No. 913.62-412 (L)] (L 0052810). Herbario L, reproducido con permiso. Lectotype of Yucca gloriosa L., Herb. Adriaan van Royen [No. 913.62-412 (L)] (L 0052810). Herbarium $L$, reproduced with authorization.

el protólogo, unicamente el de Barrelier (1714: t. 1194) está acompañado de una ilustración que puede ser utilizada como material para designar el tipo de Yucca gloriosa. Indicar que Linneo cita en su Hortus Cliffortianus (Linneo, 1738: 130) un icono de Morison (1680: 419, Sect. 4, t. 23, f. I) "Yucca foliis aloës", pero este material no fue citado directamente en el protólogo de Y. gloriosa de 1753, por lo que no puede ser considerado como original de Linneo para ser seleccionado como lectotipo del nombre.

Jarvis (2007: 931) señala como material original de Linneo cinco pliegos de herbario junto con el icono de Barrelier. El material de herbario se encuentra depositado en cuatro herbarios diferentes: Herb. Linn. No. 441.1 (LINN) (http://linnean-online.org/5300/) y Herb. Linn. No. 441.2 (LINN) (http:// linnean-online.org/5301/), Herb. Burser IV: 3 (UPS-BURSER), Herb. Clifford: 130, Yucca 1 (BM) (http://www.nhm.ac.uk/resources/ research-curation/projects/clifford-herbarium/ lgimages/BM000558544.JPG) y Herb. A. van Royen (L). El pliego Herb. Linn. No. 441.1 (LINN) conserva una flor pero ninguna hoja, al igual que el pliego Herb. Linn. No. 441.2 (LINN), que únicamente conserva dos flores, y el pliego del herbario de Clifford [Herb. Clifford: 130, Yисса 1 (BM 000558544)], que contiene cuatro flores pero ninguna hoja, por lo que no consideramos que represente un buen material para designar el tipo del nombre de Linneo. Respecto al sinónimo de Bauhin "Yucca foliis aloës", en el herbario de Joachim Burser (UPS-BURSER) se conserva un pliego con material de esta especie (Herb. Burser IV: 3) que se encuentra en buen estado de conservación. El herbario de Burser está organizado de acuerdo con la obra de su maestro Bauhin (1623), y por lo tanto esta obra y el mencionado herbario están vinculados. Este herbario estaba depositado en Uppsala cuando fue utilizado por Linneo para la interpretación de los nombres que aparecen en la obra de Bauhin (Jarvis, 2007).

Otro pliego con material original de Linneo se conserva en el herbario del Jardín Botánico de la Universidad de Leiden (Holanda), dentro de la colección de Adriaan van Royen [No. 913.62-412 (L)] (L 0052810). Este pliego contiene un espécimen más completo y en buen estado de conservación, con dos hojas y un escapo floral con seis flores. Sobre la cartulina del pliego se lee: "Cordÿline foliis pungentibus integerrimis. / Roy. prodr. 22 / Yucca foliorum margine integerrimo Linn Cliff. 130 / Yucca foliis aloe. Boerh. lugdb. 2. p. 132. / Herb. v. 
Royen”. Según indica Jarvis (2007: 153), Linneo trabajó con A. van Royen para la confección del Hortus Botanicus de Leiden durante su estancia en esta ciudad antes de partir para Suecia en 1738. Linneo consultó además del herbario de este autor su obra Florae Leydensis prodromus (Royen, 1740: 22), en la que figura lo siguiente en referencia a esta especie: "3. Cordyline foliis pungentibus integerrimis. / Yucca foliorum margine integerrimo. Linn. h. Cliff. 130 / Yucca foliis aloës. Boerh. lugdb. 2 p. 132"'. Linneo citó esta obra en el protólogo de Yucca gloriosa, bajo la indicación "Roy. lugdb. 22" tras el sinónimo "Cordyline foliis pungentibus integerrimis", sin embargo, este trabajo no está ilustrado.

En conclusión, se considera como el mejor candidato a lectotipo del nombre Yucca gloriosa el pliego de la colección de A. van Royen, conservado en el herbario de Leiden [Herb. A. van Royen (L)], ya que es bastante completo y muestra un buen estado de conservación, permitiendo al tiempo conservar el uso tradicional y actual del nombre linneano de esta especie.

Yucca gloriosa L., Sp. Pl.: 319 (1753)

Ind. loc.: "Habitat in Canada, Peru"

Lectotypus (hic designatus): Herb. Adriaan van Royen [No. 913.62-412 (L)] (L 0052810) (fig. 1).

AGRADECIMIENTOS. Al Dr. Mats Hjertson (Museum of Evolution, Botany Section Uppsala University) por su ayuda en el estudio del herbario UPS-BURSER. Al Dr. Gerard Thijsse y Dra. Roxali Bijmoer (Nationaal Herbarium Nederland, Leiden University branch, Holanda) por su ayuda en el estudio de la colección de Adriann van Royen del herbario L.

\section{BIBLIOGRAFÍA}

BARRELIER, J. -1714- Plantae per Galliam, Hispaniam et Italiam Observatae, Iconibus Aeneis Exhibitae. Stephanum Ganeau. Parisiis
[Paris].

BAUHIN, C. -1623-Pinax theatri botanici, ed. 2. Basileae Helvet.: Sumptibus \& typis Ludovici Regis, Switzerland.

HÖCHSTATTER, F. -2002- Yucca II (Agavaceae). Indehiscent-fruited species in the Southwest, Midwest and East of the USA. Selbst Verlag. Germany.

HOUTTE, L. van -1880- Flore des Serres et des Jardins de l'Europe. Vol. XXIII Gand, Belgique.

IRISH, G. \& IRISH, M. -2000-Agaves, yuccas and related plants. A gardener's guide. Timber Press. Portland. Oregon.

JARVIS, C. E. -2007-Order out the Chaos. Linnean plant names and their types. The Linnean Society of London in association with the Natural History Museum, London. London.

LINNEO, C. -1737. Viridarium Cliffortianum. Amsterdam.

LINNEO, C. -1738- Hortus Cliffortianus. Amsterdam.

LINNEO, C. -1748- Hortus Upsaliensis. Stockholm. Impensis Laurentii Salvii.

LINNEO, C. -1753-Species Plantarum. Stockholm: Impensis Laurentii Salvii.

MOLON, G. -1914- Le yucche, noioni botaniche, specie, varietà, íbridi usi economici. Ed. Ulrico Hoepli. Milano.

MORISON, R. -1680-Plantarum historiae universalis Oxoniensis pars secunda. Oxford.

ROYEN, A. van-1740- Florae Leydensis prodromus, exhibens plantas quae in horto académico Lugduno-Batavo aluntur. Leiden.

SCHWERIN, G. von-1920-Mitteilungen (Jahrbuch) der Deutschen Dendrologischen Gesellschaft. Deutsche Dendrologische Gesellchaft. Thyrow (Kr. Teltow).

TRELEASE, W. -1902- The Yuccae. Rep. (Annual) Missouri Bot. Garden 13: 68-71.

Dirección de los autores. ${ }^{1}$ Servicio de Vida Silvestre. Centro para la Investigación y Experimentación Forestal (CIEF). Conselleria d'Infraestructures, Territori i Medi Ambient. Generalitat Valenciana. Av. Comarques del País Valencià, 114. E-46930. Quart de Poblet, Valencia, España. ${ }^{2}$ VAERSA. Avda. Cortes Valencianas, 20. E-46015, Valencia, España. Daniel

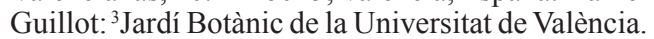
C/ Quart 82, E-46008, Valencia, España. *Autor para correspondencia: flora.cief@gva.es 